Article

\title{
An Innovative Green Process for the Stabilization and Valorization of the Organic Fraction of Municipal Solid Waste
}

\author{
Carola Esposito Corcione *(D), Francesca Ferrari, Raffaella Striani, Stefania Minosi, \\ Mauro Pollini ${ }^{D}$, Federica Paladini ${ }^{D}$, Angelica Panico, Roberto De Fazio, Paolo Visconti ${ }^{D}$ and \\ Antonio Greco \\ Dipartimento di Ingegneria dell'Innovazione, Università del Salento, 73100 Lecce, Italy; \\ francesca.ferrari@unisalento.it (F.F.); raffaella.striani@unisalento.it (R.S.); stefania.minosi@gmail.com (S.M.); \\ mauro.pollini@unisalento.it (M.P.); federica.paladini@unisalento.it (F.P.); angela.panico@unialento.it (A.P.); \\ defazio_roberto@libero.it (R.D.F.); paolo.visconti@unisalento.it (P.V.); antonio.greco@unisalento.it (A.G.) \\ * Correspondence: carola.corcione@unisalento.it
}

Received: 24 September 2019; Accepted: 21 October 2019; Published: 24 October 2019

\begin{abstract}
This work is aimed at the development of innovative, easy and cheap methods for the stabilization, inertization and valorisation of the organic fraction of municipal solid waste (OFMSW). For the first time, two original processes for transforming the organic waste into an inert, odorless and sanitized material were here proposed. The first one, called dual step, starts with grinding of the OFMSW, by means of an industrial shredder. After being finely ground, the organic waste was exposed to a sterilization process by means of UV/ozone radiations or thermal treatment (stabilization phase) in order to obtain a complete removal of the OFMSW's bacterial activity. By means of several microbiological analyses, the best sterilization method was chosen. The incorporation in a thermosetting matrix was, then, carried out through mixing the sterilized and finely ground organic waste into a water soluble urea formaldehyde (UF) based resin, with a formaldehyde content less than $1 \% \mathrm{wt}$, followed by a thermal treatment for UF-resin crosslinking (inertization phase). An alternative cheaper and easier process, called one step, was also proposed and investigated, by combining the sterilization with the curing thermal process (at higher temperature) of the thermosetting matrix. The preliminary experimental results reported in this paper suggest that both the proposed methods could be considered suitable for the production of high valorized innovative OFMSW-derived panels or bricks that could find application in several fields, such as building or construction materials. Finally, a brief description of the prototype machinery, properly designed for implementing OFMSW stabilization and valorization processes, is reported.
\end{abstract}

Keywords: waste; OFMSW; inertization; valorization; urea formaldehyde resin; valorized products reuse

\section{Introduction}

One of the major challenges in waste management and disposal are the excessive waste streams deriving from the different sectors of the current linear economic model. Municipal waste accounts for only about $10 \%$ of the total waste generated [1]. Municipal solid waste consists of waste collected by or on behalf of municipal authorities and disposed through the waste management system [2]. The amount of municipal solid waste, globally collected per year, is approximately $1.3 \times 10^{12} \mathrm{t}$ and it is expected to rise up to $2.2 \times 10^{12}$ t per year by 2025 [3].

Municipal solid waste contains a significant fraction of paper, food waste, wood and yard trimmings, cotton, glass, metals and leather, as well as derivatives of fossil raw materials such as 
plastics [1]. Some $46 \mathrm{wt} \%$ of European municipal solid waste is organic waste, below to referred as OFMSW, composed of food waste deriving from homes, restaurants and markets. Specifically, the European Union (EU) produces $8.9 \times 10^{7} \mathrm{t}$ of organic municipal solid waste per year and this amount is expected to rise to $1.26 \times 10^{8}$ t by 2020 [4]. Domestic waste and waste from industrial processing represent the major part in the total amount of municipal solid waste (relatively only the EU produces about $47 \times 10^{6} \mathrm{t}$ of domestic waste and about $17 \times 10^{6} \mathrm{t}$ of waste from industrial processing) [5]. Due to the significant quantities of organic municipal solid waste produced worldwide and the consequent negative environmental impact, local, national and European authorities have undertaken various activities finalized towards the implementation of different management solutions regarding this type of waste. Recently, Cobo et al. [6] developed a model able to optimize the flows of organic waste and their management by considering the circularity and sustainability criteria. Nevertheless the complexity of the superstructure comprising different management technologies, the same authors declared in their first study that: "the complete circularity of the nutrient flows within any Circular Integrated Waste Management System is infeasible" [6]. Afterwards, Cobo et al. [7] improved their model in order to recover nutrients from the municipal organic waste by considering typology, life cycle and costs.

Conventional techniques widely applied for the treatment and management of organic waste in developing countries consist of animal feeding, composting, anaerobic digestion, incineration and disposal in landfills [8]. Disposal in landfills causes several environmental issues including emissions of greenhouse gas, unpleasant smell production and the formation of leachate. Due to the composition of organic waste and the high water content, incineration is an energy demanding and inefficient process that also entails air pollution [8]. Composting is a process during which the organic materials are converted into low value-added products [8]. On the other hand, thermochemical conversion processes (e.g., pyrolysis, gasification, liquefaction) and bio-chemical conversion methods (e.g., anaerobic digestion, fermentation, microbial fuel cell) are more advanced approaches for the treatment and management of organic waste in conjunction with the potential to produce value-added bio-based chemicals, polymers, fuels and energy [9]. Through the development of proper methods and systemic approaches, different types of biogenic wastes can be converted into diversified types of bio-energy products (e.g., biogas, syngas, methane, hydrogen, electricity), targeting various market outlets under the framework of a circular economy [2]. Mirabella et al. presented a summary of the different aspects of the valorization of vegetable and fruit wastes for the extraction of bioactive compounds and nutrients [10]. An innovative approach for the valorization of bakery waste for the production of bio-colorants has been proposed by Haque et al. [11]. Agro-industrial, dairy and food processing wastes have been recently used for the production of bio-surfactants [12].

Though the production of biogas is a valid method to recycle organic waste, it cannot be used in some situations where a long disposal period can cause the proliferation of bacterial loads and the production of bad smells, such as for example on cruise ships. As in the past [13], the problem of biomass storage is still current. The in-depth study of Barhs [14] on the evolution over the years of biogas exploitation for the production of energy and the insights of Mangold et al. [15] about the influence of collection date and the ensiling on the yield for the methane production by the Miscanthus genotypes, prove that an important limit for anaerobic digestion is the storage, so continuous feeding is necessary in biogas plants. The use of organic waste for the realization of bio-products was also recently analyzed. Cerda et al. [16] discussed solid-state fermentation (SSF). In dry conditions the waste material (solid biomass) can become a substrate for bio-transformations for producing aromas, biosurfactants, biopesticides, bioplastics, organic acids or phenolic compounds. However, an important issue associated with the use of the organic waste is its heterogeneity. The aim of this paper is, hence, the design of an innovative, easy and cheap method for the stabilization (i.e., sterilization) and valorization of the organic fraction of municipal solid waste (here in after OFMSW), by its incorporation in a thermosetting polymeric resin for the production of fully inert panels. This process is extremely robust and reliable, being the quality of the produced panels substantially independent of the nature of 
OFMSW. The panels produced in this work are odorless and completely sterile, allowing for easy storage. The mechanical properties of the samples produced allow their use for further applications, such as for the replacement of MDF panels, for the production of garden and outdoor furniture items or for thermal-acoustic insulation by providing an added value to the product. Moreover, the developed OFMSW's transformation process is robust (towards parameters and variables that can influence it), reliable and above all independent of the nature, intrinsically non-homogeneous, of the processed OFMSW for obtaining reproducible technical features of the manufactured products or panels for each considered application. In particular, the main applications identified for the machinery products, in form of bricks or panels, constituted by OFMSW and UF resin are:

- $\quad$ Thermal or acoustic insulating panels for building application;

- Medium-density fibreboard (MDF)-like panels for building applications;

- Garden or outdoor furniture items.

The mechanical tests carried out confirmed that the produced panels are not suitable for the production of structural elements, but they can be used for not structural applications (e.g., as filler of non-structural elements in place of chipboard or blockboard panels) [17] and for indoor and outdoor furnishings. Specifically, the realized bricks can be used for realizing panels to be covered in order to hide the unavoidable imperfections (e.g., sandwich panels with coverage through wooden sheets); they can't be used for decorative applications or, in general, in the case of visible uses, because they have residual defects (mm-scale depressions or roughness) arising from the OFMSW transformation process. For instance, these eco-compatible products could be employed as filler for interior doors, filler panels for the interior of non-visible parts of the ships (as an alternative to poplar boards), backrests of sofas or chairs, where no particular mechanical property is required, as instead required for the seat. Finally, the designed prototype machinery could be used, by employing molds with different shapes, to produce the finished products directly, as gardening pots, flowerpots or garden furnishings, with the obvious advantage as no other company would be needed.

The primary step of this work includes the development of efficient method for the bacterial load removal (i.e., stabilization step), by using conventional sterilization methods. Satisfactory evaluation of a new preservation technology depends on reliable estimation of its efficacy against pathogenic and spoilage food-borne microorganisms. Research on alternative technologies was initially focused on process design, product characteristics and kinetics of microbial inactivation. The success of these new technologies, however, depends on progress in understanding microbial physiology and behavior of microbial cells during and after treatment [18]. Among them, UV and ozone radiation could be considered suitable for our aim to eliminate bacteria from OFMSW.

The second step for the production of panels involved the incorporation of the OFMSW into a thermoset matrix (i.e., sterilization step). The pre-polymerized UF-based commercial resin SADECOL P 100N (Sadepan Chemical Company, Mantova, Italy city, state abbrev if USA, country), employed during the experimental activity for the OFMSW inertization step, is featured by a formaldehyde content less than $1 \% \mathrm{wt}$ (on average $0.5 \% \mathrm{wt}$ ); it is nowadays widely used around the world by companies for producing wood-based panels and furniture, also derived from recycled wood and, compared to other polymeric matrices, and it has enabled us to overcome several technical issues concerning the present research project thanks to its high solubility in water, rapid curing process times at relatively low temperature and not least, a low cost.

Commercial panels and furniture made by different companies from recycled wood by using the Sadecol be consistent in capitalization P $100 \mathrm{~N}$ resin have been already classified as low emission E1-class products, due to very low release of free formaldehyde in the air, according to the EN 120 and EN 717 European standards and, consequently, they can be used without generating a free-formaldehyde equilibrium concentration above $0.1 \mathrm{ppm}$, the upper limit fixed by the World Health Organization for living areas. 
Finally, after reporting the results on the optimization of OFMSW's sterilization, inertization and valorization processes and on the mechanical and chemical properties of the manufactured products, a brief description of the prototype machinery designed for the subsequent engineering of the entire OFMSW transformation process is reported, together with some 3D images showing the functional units of the designed machinery.

\section{Materials and Methods}

The OFMSW used in this paper is a variegate waste from the restoration sector, consisting mainly of food scraps and food preparation derivatives. The thermosetting resin used in this work for the inertization of OFMSW is a urea formaldehyde (UF) powder polymer, produced by Sadepan Chemical Company as SADECOL P $100 \mathrm{~N}$. It is supplied as fine powder/granules with defined grain size and a viscosity of $60 \div 130 \mathrm{mPa}$ s at $20^{\circ} \mathrm{C}$. The first proposed OFMSW transformation process is called dual step, since the reduction of the bacterial activity and the setting reaction of the polymeric matrix are performed separately. In this process, the OFMSW is firstly subjected to a grinding process followed by stabilization, which is performed by means of UV/ozone exposure or a thermal treatment. After, the stabilized and finely ground OFMSW and UF powder are mixed in a water slurry, which can be processed by a pressure-free process, as reported in the scheme of Figure 1.

\section{DUAL STEP PROCESS}

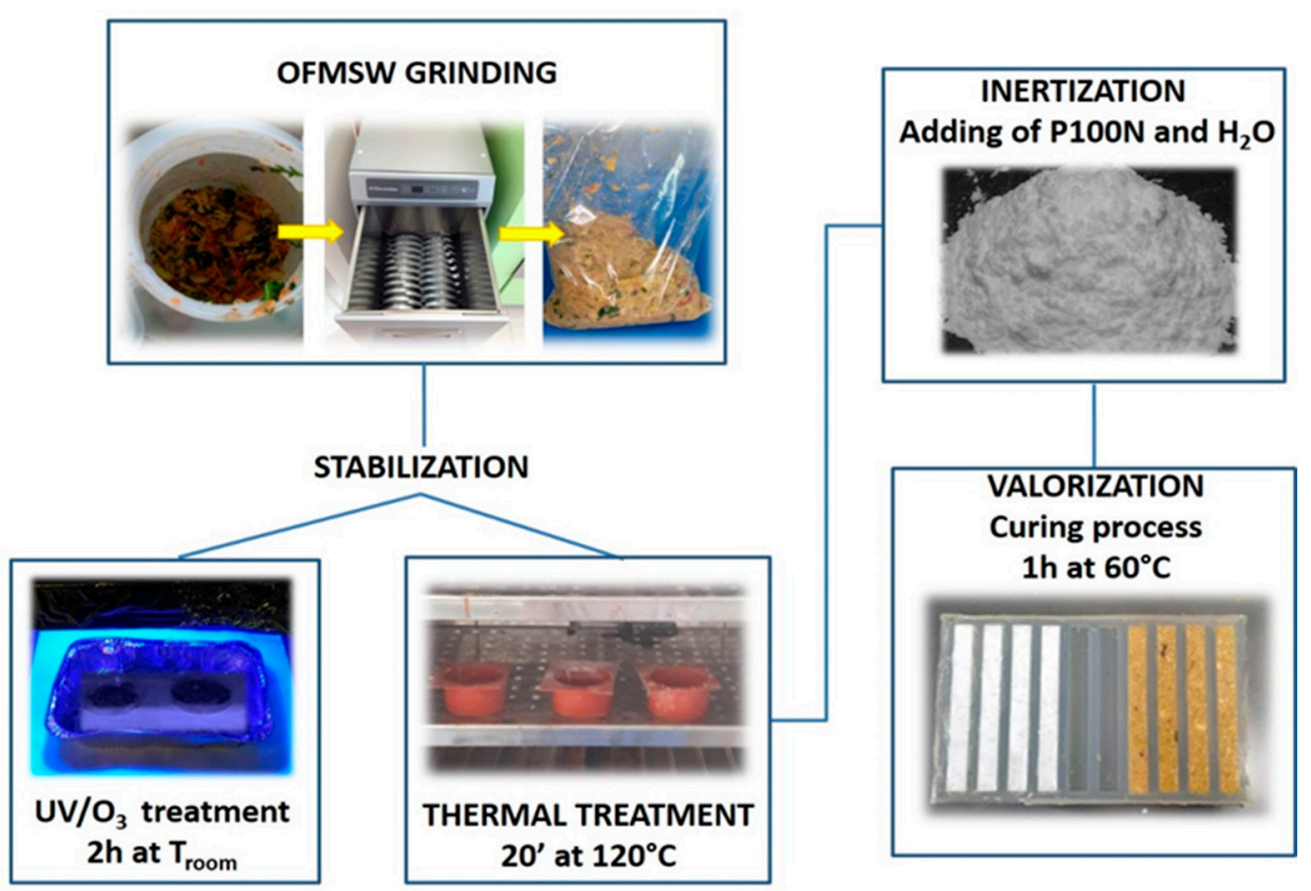

Figure 1. Simplified scheme relative to the dual-step OFMSW-treatment process.

The water content for each ground OFMSW batch was evaluated by thermogravimetric analysis (TGA); for this purpose, a Netzsch STA 409 simultaneous thermal analyzer (Netzsch, Verona, Italycity, state abbrev if USA, country) was used, heating samples from room temperature to $700{ }^{\circ} \mathrm{C}$ with a heating rate of $10^{\circ} \mathrm{C} / \mathrm{min}$ in $\mathrm{N} 2$ atmosphere. Ten replicates were performed in order to measure the water amount in OFMSW.

The stabilization step, i.e., the sterilization of the OFMSW, was performed by means of:

(a) UV/ozone treatment. The UV/ozone radiation method was implemented by means of a $\mathrm{Hg} \mathrm{UV}$ lamp (HG 1000 ULTRA, JELOSIL Srl, Vimodrone MI, Italy company, city, state abbrev if USA, 
country) with a radiation intensity on the surface of the sample of $9.60 \mathrm{~W} / \mathrm{mm}^{2}$, working in air atmosphere. The ground OFMSW samples were exposed to Hg UV lamp irradiation for a time ranging from $1 \mathrm{~h}$ to $5 \mathrm{~h}$.

(b) Thermal treatment. Three different thermal treatments were performed by exploiting humid or dry conditions.

- OFMSW was exposed to $\mathrm{T}=100{ }^{\circ} \mathrm{C}$ for $20 \mathrm{~min}$ (with relative humidity of $90 \%$ ) in a climatic chamber (Binder, Guangdong, China city, state abbrev if USA, country).

- OFMSW was exposed at $\mathrm{T}=100{ }^{\circ} \mathrm{C}$ for $30 \mathrm{~min}$ (dry environment) in an oven (Lenton, Hope Valley, UK city, state abbrev if USA, country).

- OFMSW was exposed at $\mathrm{T}=120^{\circ} \mathrm{C}$ for $20 \mathrm{~min}$ (dry environment) in an oven (Lenton).

The effectiveness of each sterilization method was evaluated by means of in-vitro microbiological tests by spreading OFMSW treated samples on agar plates. Nutrient agar $(0.3 \% \mathrm{wt} / \mathrm{v}$ beef extract, $0.5 \%$ $\mathrm{wt} / \mathrm{v}$ peptone, $1.5 \% \mathrm{wt} / \mathrm{v}$ agar) was used as a non-selective medium supporting growth of a wide range of organisms. The agar medium was pre-sterilized in an autoclave at $121^{\circ} \mathrm{C}$ for $30 \mathrm{~min}$ and dispensed into Petri dishes. The agar plates were allowed to solidify for about $30 \mathrm{~min}$ in a biosafety cabinet. Each sample was picked up with a sterile inoculating loop and spread over the surface of the medium. Then, the plates were incubated at $37^{\circ} \mathrm{C}$ overnight and, after incubation, they were visually inspected for macroscopic growth of bacterial colonies.

In the inertization step, stabilized OFMSW was mixed with water and UF-based SADECOL $P$ $100 \mathrm{~N}$ resin, in order to produce a slurry, which was then cured at $\mathrm{T}=120^{\circ} \mathrm{C}$ for $1 \mathrm{~h}$. After curing and water evaporation, a UF/ OFMSW composite was obtained, which was characterized by means of thermal, physical and mechanical tests. For comparison purpose, a formulation without OFMSW was also realized. The compositions of the two mixtures produced by the two step process (P100N UF, OFMSW_P100N UF) are reported in Table 1. As preliminary approach, the ratio 70/30 between the solid phase (which includes the matrix and the dried OFMSW) and water was chosen. Tests on different compositions are shown in the second part of the present paper [17].

Table 1. Blends composition (dual step process).

\begin{tabular}{cccc}
\hline Formulations & Water (\%) & P100N (\%) & Dried OFMSW (\%) \\
\hline P100N & 30 & 70 & 0 \\
OFMSW_P100N & 30 & 57 & 13 \\
\hline
\end{tabular}

A further simplified transformation process was also employed in order to reduce time duration and costs. Compared to the dual-step process, the one-step process allows performing the reduction of the bacterial activity simultaneously with the curing of the thermosetting matrix. Also, the addition of the slurry without any preliminary treatment avoids further addition of water, exploiting the water contained in the OFMSW.

To this aim, the blend of wet OFMSW and UF was heated at a temperature of $120^{\circ} \mathrm{C}$ and kept at the same temperature for $1 \mathrm{~h}$ for allowing in the same time the reduction of the bacterial charge and the curing of the UF-based matrix. All the process is summarized in the simplified scheme of Figure 2. 


\section{ONE STEP PROCESS}

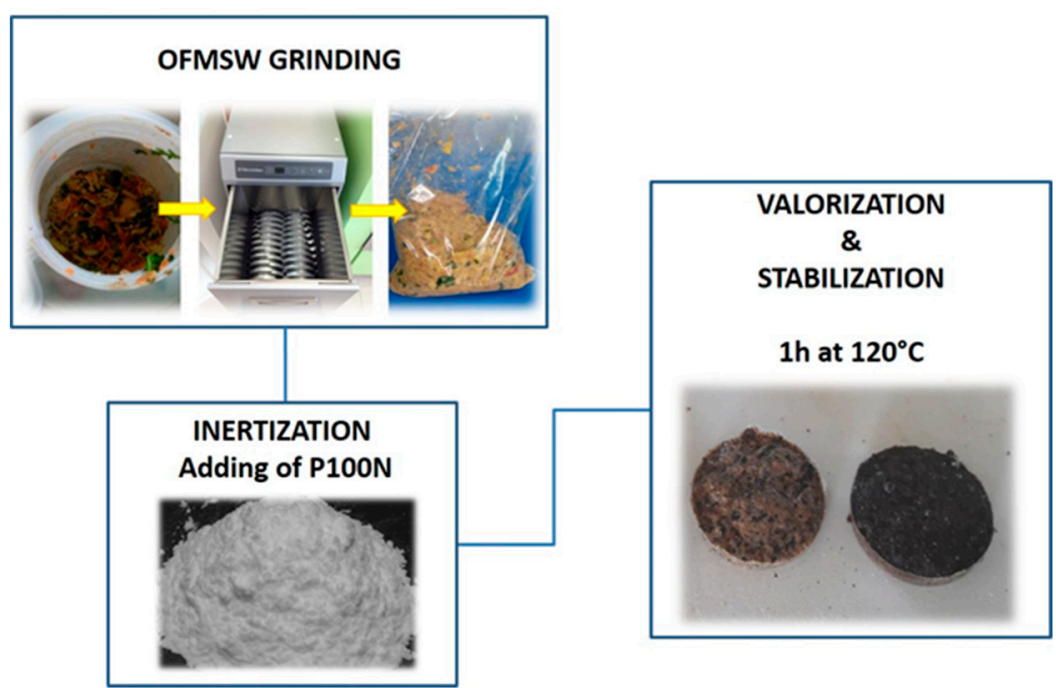

Figure 2. Simplified scheme relative to the one step OFMSW-treatment process.

In the case of one step method, different additives, wastes (i.e., coffee powder) or recycling materials (i.e., sawdust), were also added to the OFMSW/P100N UF composites in order to evaluate their effect on physical-mechanical properties of the one step processed samples. The compositions of the one step cured samples, with and without the wastes additives are reported in Table 2.

Table 2. Blends composition (one step process).

\begin{tabular}{cccccc}
\hline Formulations & Water (\%) & P100N UF (\%) & $\begin{array}{c}\text { Dried OFMSW } \\
\mathbf{( \% )}\end{array}$ & $\begin{array}{c}\text { Coffee } \\
\text { Powder }\end{array}$ & Sawdust \\
\hline OFMSW_P100N_one step & 30 & 57 & 13 & 0 & 0 \\
OF_MSWP100N_10c_one step & 30 & 47 & 13 & 10 & 0 \\
OFMSW_P100N_10s_one step & 30 & 47 & 13 & 0 & 10 \\
\hline
\end{tabular}

Rheological analyses were carried out by using a Rheometrics Ares rheometer (TA, New Castle, DE company, city, state abbrev if USA, country). Dynamic tests were performed from room temperature to $140{ }^{\circ} \mathrm{C}$ at a heating rate of $3{ }^{\circ} \mathrm{C} / \mathrm{min}$. In order to determine the time necessary to complete the curing reaction, a further isothermal rheological analysis at $120^{\circ} \mathrm{C}$ was performed; a double plate geometry was used, setting a gap of $0.3 \mathrm{~mm}$, constant oscillatory amplitude $(1 \%)$ and frequency equal to $1 \mathrm{~Hz}$.

All the mixtures were poured in silicon molds and put in a static oven at $120{ }^{\circ} \mathrm{C}$ for the time necessary to complete the cure reaction (i.e., $1 \mathrm{~h}$ ).

Flexural tests were performed on six samples $(100 \mathrm{~mm} \times 10 \mathrm{~mm} \times 3 \mathrm{~mm})$ obtained after inertisation, using a Lloyd LR5K dynamometer (Lloyd Instruments, Roma, Italy city, state abbrev if USA, country) and a crosshead speed of $1.5 \mathrm{~mm} / \mathrm{min}$.

An AXIO-LINKAM optical microscope (Zeiss, Milano. Italycity, state abbrev if USA, country) was used for the morphological characterization of the materials. The size of the pores was obtained as an average of 50 measurements.

Analysis of variance (ANOVA) was used to highlight the statistical significance of different parameters, as the different processes or the different additives on the mechanic properties. To this purpose, the F value, which is defined as the ratio of the variation between sample means to the variation within the samples, was calculated from the measured data. Then, being "a" the number of levels of the variance factor, and " $n$ " the number of tests for each level, the critical F value, FCV(a-1, $a(n-1), \alpha)$, can be estimated. FCV represents the value of F distribution with degrees of freedom (a-1) 
and a(n-1), which, at a confidence level, $\alpha$, corresponds to the null hypothesis (equivalence of the means). $\mathrm{F}<\mathrm{FCV}$ indicates that the population means are equivalent, while $\mathrm{F}>\mathrm{FCV}$ indicates that the population means are significantly different [19]. Another quantitative measure for reporting the result of a test of hypothesis is the $p$-value. The $p$-value is the probability of the test statistic to be at least as extreme as the one observed, given that the null hypothesis is true. A small $p$-value is an indication that the null hypothesis is false. It is good practice to decide in advance of the test how small a $p$-value is required to reject the test, that is, to choose a significance level, $\alpha$, for test. For example, it can be decided to reject the null hypothesis if the test statistic exceeds the critical value (for $\alpha=0.05$ ) or, analogously, to reject the null hypothesis if the $p$-value is smaller than 0.05 .

\section{Result}

The typical TGA and derivative (DTG) curves for OFMSW are reported in Figure 3. A; the TGA curve highlights a first weight loss occurring up to $150^{\circ} \mathrm{C}$, which is attributed to water evaporation from OFMSW. This result is confirmed by the DTG curve, showing the presence of two endothermic peaks from room temperature to $150{ }^{\circ} \mathrm{C}$. For such a reason, it is possible to estimate an average water content in OFMSW of $65 \pm 5 \%$. Further weight losses of the analyzed OFMSW are observed between 300 and $650^{\circ} \mathrm{C}$, which are attributed to thermo-oxidative degradation of the organic fraction of OFMSW. The degradation is again confirmed by DTG curves; in particular, two stronger endothermic peaks are visible at about 300 and $400{ }^{\circ} \mathrm{C}$, then a lighter peak occurs until $600{ }^{\circ} \mathrm{C}$.

\section{A}

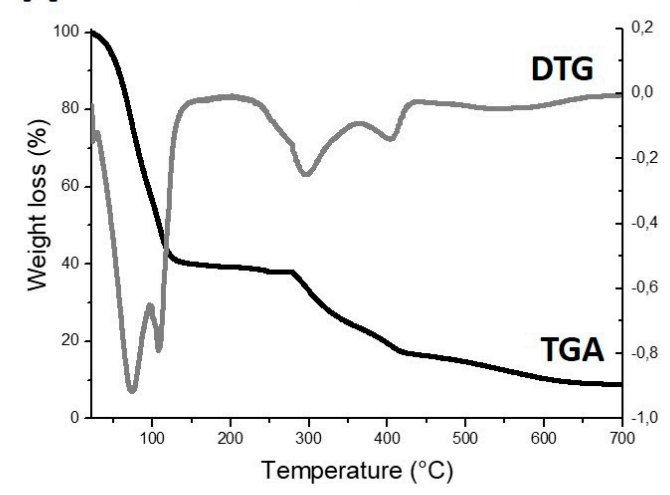

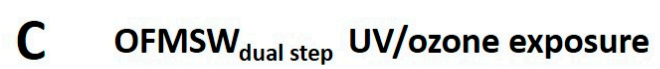

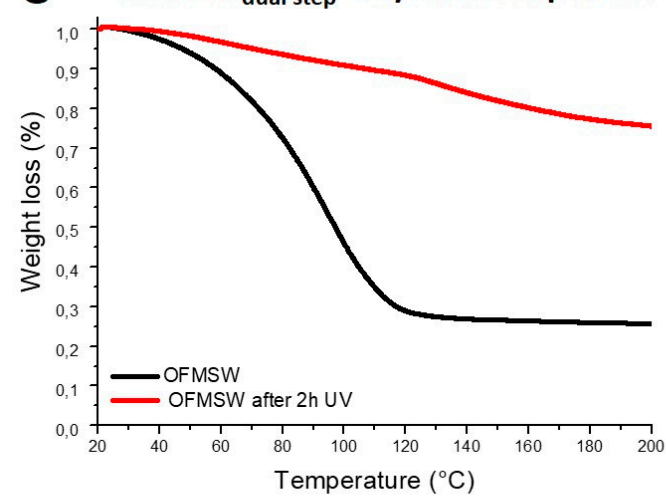

\section{B $\quad$ OFMSW $_{\text {dual step }}-$ UV/ozone treatment}

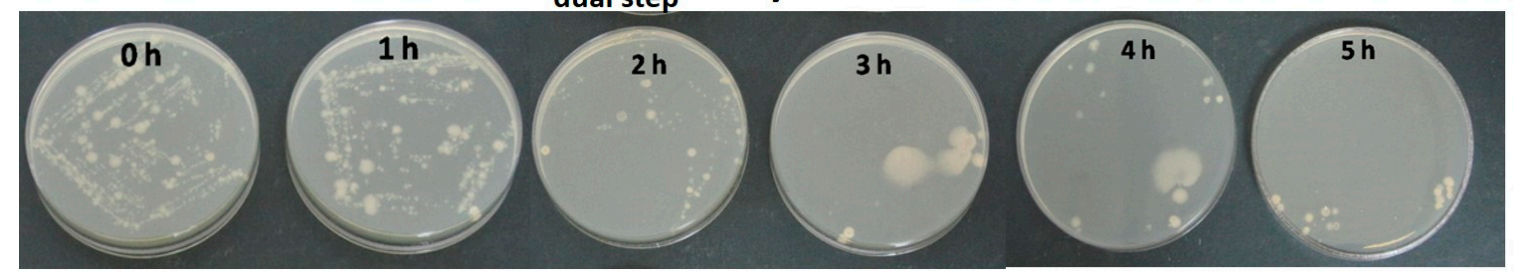

Figure 3. (A) TGA and derivative (DTG) curves of OFMSW; (B) Bacterial growth on OFMSW samples subjected to UV/ozone stabilization; (C) Enlargement $\left(25^{\circ} \mathrm{C}-200{ }^{\circ} \mathrm{C}\right)$ of TGA curves of OFMSW before and after $2 \mathrm{~h}$ UV/ozone treatment.

\subsection{Dual-Step Process}

In order to identify the most effective process for stabilizing the organic fraction of solid waste (OFMSW), two different methods have been performed on the grinded OFMSW: UV/ozone radiations and thermal treatments.

Figure 3B reports the results obtained by microbiological tests performed on OFMSW samples exposed to UV/ozone radiations as a function of time exposure, ranging from $1 \mathrm{~h}$ to $5 \mathrm{~h}$. The untreated 
sample showed a high level of contamination by different types of bacteria, as demonstrated by the presence of colonies with different shape, size and pigmentation on the agar plate. After $2 \mathrm{~h}$ of UV/ozone treatment, the bacterial growth starts to decrease and, although non-completely removed, it was further reduced until $5 \mathrm{~h}$. Unfortunately, longer UV/ozone exposure caused the degradation of the organic fraction. For these issues, a time of exposure equal to $2 \mathrm{~h}$ was selected to obtain an adequate compromise time-effectiveness avoiding damage of OFMSW. Besides reduction of the bacterial activity, UV/ozone treatment also caused a significant water evaporation, as observed by TGA analysis reported in Figure $3 \mathrm{~A}$ and by the enlargement of the TGA curves ranging from $25^{\circ} \mathrm{C}$ to $200{ }^{\circ} \mathrm{C}$, reported in Figure $3 \mathrm{C}$. The TGA curves evidence that the residual water content of the OFMSW after a two-hour long irradiation process with UV lamp is about $12 \%$.

In order to overcome the low effectiveness of UV/ozone stabilization process, another sterilization technique was explored by using a thermal treatment [20]. Microbiological tests performed on each OFSMW sample after each thermal treatment investigated are reported in Figure 4.

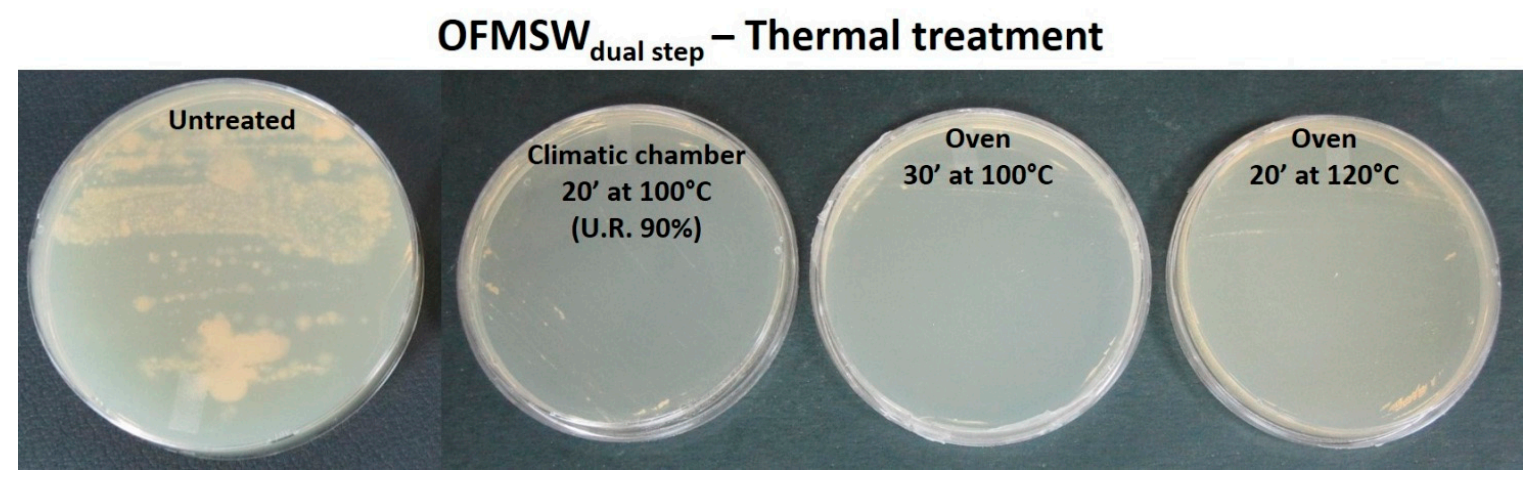

Figure 4. Bacterial growth on OFMSW samples subjected to thermal treatment.

By comparing the microbiological results reported in Figure 4, it is evident that all the thermal treatments were effective to completely sterilize the OFMSW samples. In Figure 4, the untreated sample resulted fully contaminated with a wide variety of microorganisms while no growth of bacterial colonies was observed on the plates related to the treated samples. High temperatures effectively killed the microorganisms; nevertheless, the third treatment $\left(20 \mathrm{~min}\right.$ at $\left.120^{\circ} \mathrm{C}\right)$ was selected as the most convenient sterilization treatment in terms of times, feasibility and efficacy, even if it causes an almost full removal of the water content.

In addition, the dual-step process allowed obtaining samples which are characterized by adequate mechanical properties, as following reported. However, the process is quite inefficient from the energetic and materials consumption point of view. In facts, starting from a OFMSW very rich in water, this is firstly heated to remove bacterial activity. Despite the fact that the use of a climatic chamber allows reducing the water loss, when working in a forced convection oven, water is completely evaporated. In any case further water must be added to produce the slurry, which is again heated up to $120^{\circ} \mathrm{C}$ to allow matrix curing (see Figure 1). Combining sterilization and curing was attained in a single step process, with the advantage that the material is heated only once up to $120^{\circ} \mathrm{C}$ and no further water is added to the slurry.

\subsection{One-Step Process}

The OFMSW/P100N/water slurry was poured in a mold, without any previous sterilization treatment, and kept at $120^{\circ} \mathrm{C}$ for $1 \mathrm{~h}$.

The bacterial analyses performed on the one step OFMSW_P100N processed sample, reported in Figure 5, confirmed the efficiency of the one step treatment in the full elimination of bacteria. After incubation, no bacterial colonies were observed on the plates confirming the successful sterilization of the sample. 


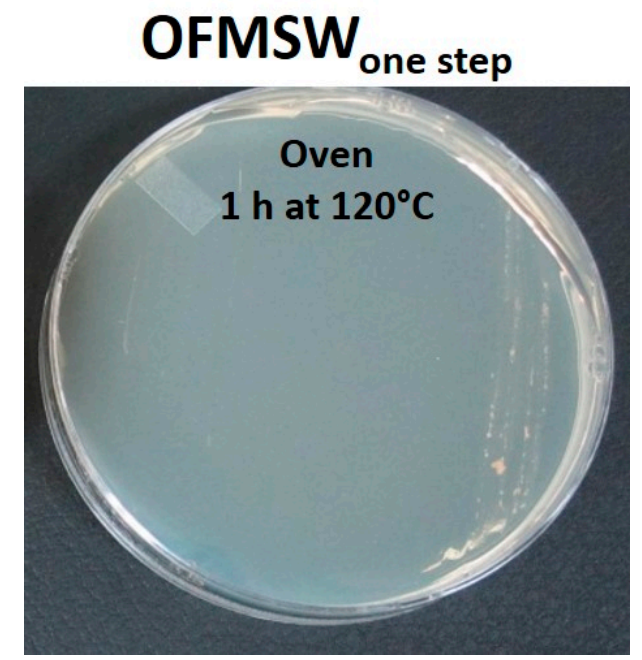

Figure 5. Bacterial analysis on OFMSW sample subjected to the one-step process.

In order to evaluate the effect of OFMSW on the matrix curing process, a dynamic rheological analysis of the two formulations of Table 1 (P100N and OFMSW_P100N) was firstly carried out.

Results of dynamic rheological analyses, shown in Figure 6A, highlight the presence of different steps:

- A first step, up to $110{ }^{\circ} \mathrm{C}$, which involves a decrease in viscosity due to the presence of the water. Although the viscosity decrease occurs approximately with the same rate for both systems, the presence of the OFMSW involves a strong increase of the starting value of the viscosity. This result must be considered for the processability of the system, since higher viscosities at room temperatures imply higher times to fill the mold before the cure.

- A second step from $110{ }^{\circ} \mathrm{C}$ to $120^{\circ} \mathrm{C}$, characterized, for both systems, by a sharp increase in viscosity, due to the starting of the cure.

- A third step, up to $200{ }^{\circ} \mathrm{C}$, where a further increase in viscosity is visible for both curves; this growth is due to both water evaporation and cure of the system. Nevertheless, as previously discussed for PVA/OFMSW/water system [21], the presence of OFMSW involves a decrese in the evaporation rate of the water. As clearly visible in Figure 3A, the slope of the curve in this range and the final viscosity achieved are lower for the system with OFMSW.

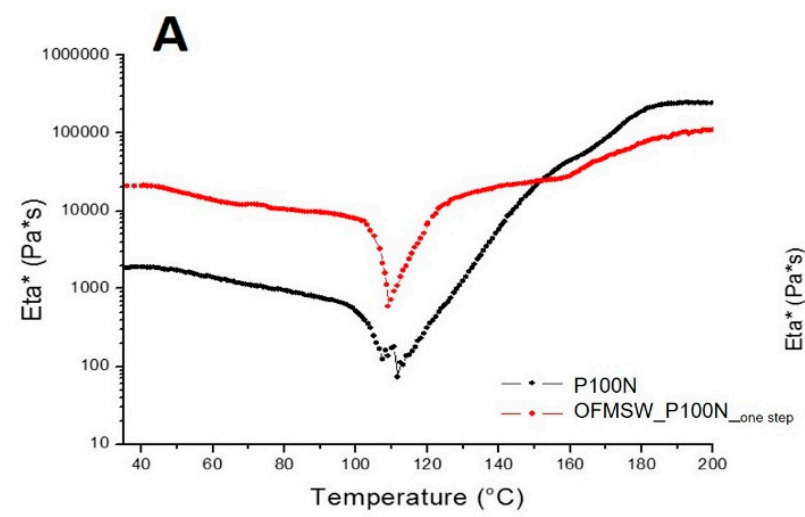

\section{B}

Figure 6. (A) Dynamic rheological curve of P100N and OFMSW_P100N_one step; (B) isothermal rheological curves at $120^{\circ} \mathrm{C}$ of P100N and OFMSW_P100N_one step. 
After, an isothermal rheological analysis was also performed at $120^{\circ} \mathrm{C}$ on both systems in order to evaluate the curing time. The results reported in Figure $6 \mathrm{~B}$ show that $60 \mathrm{~min}$ are enough to complete the reaction at $120^{\circ} \mathrm{C}$ for both the mixtures.

The results from rheological analysis allowed assessing an optimum curing process at $120{ }^{\circ} \mathrm{C}$ for $60 \mathrm{~min}$ for the production of solid samples, as reported in the inset of Figure 1, for the following physical-mechanical characterizations.

Figure 7 shows the microscopy images of all the samples produced in this work. The average dimension of the pores for each sample is shown in Table 3. By comparing the microscope images reported in Figure 7, it is clearly noticeable that the introduction of OFMSW strongly decreases the porosity with respect of the P100N system in both dual step (Figure 7B) and one step (Figure 7C) processes. In fact, the averages pores diameter of the OFMSW_P100N $\mathrm{dual}_{\text {step }}$ and OFMSW_P100N $N_{\text {one step }}$ reported in Table 3 are almost comparable. However, the one-step process involves a slight increase in the porosity of the sample.

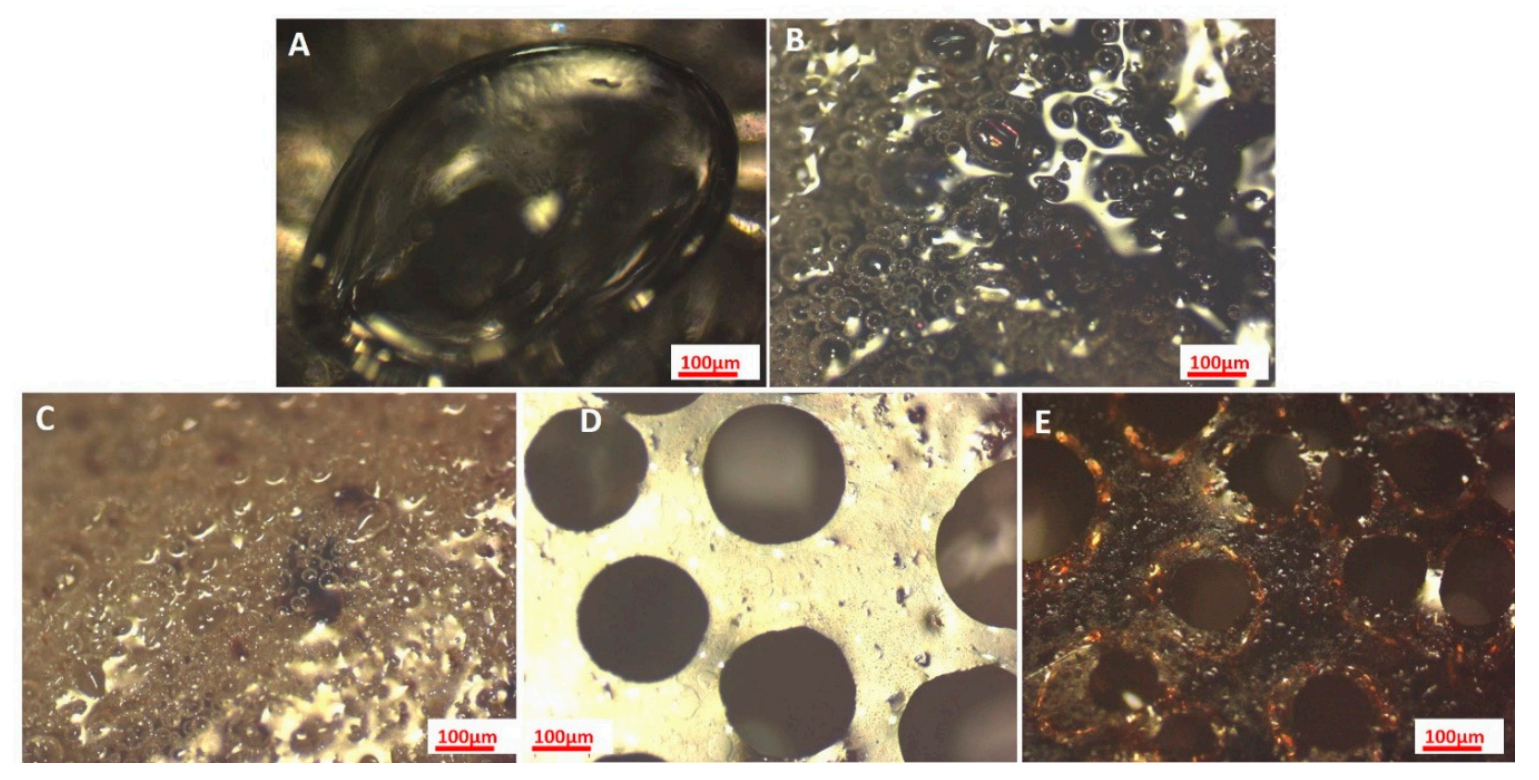

Figure 7. Optical microscope analysis of P100N (A), OFMSW_P100N dual step (B), OFMSW_P100N (C), with sawdust as additive - OFMSW_P100N_10s_one_step (D) and with coffee powder added OFMSW_P100N_10c_one_step. (E) samples (magnification 50X).

Table 3. Average dimension of the pores of one step and dual step process cured samples.

\begin{tabular}{cc}
\hline Sample & Average Pores Diameter $(\mu \mathrm{m})$ \\
\hline P100N & $691.39 \pm 205.01$ \\
OFMSW_P100N & $50.48 \pm 24.65$ \\
OFMSW_P100N one step $_{\text {one }}$ & $68.94 \pm 34.83$ \\
OFMSW_P100N_10s one step & $260.35 \pm 32.77$ \\
OFMSW_P100N_10c one step & $151.48 \pm 14.68$ \\
\hline
\end{tabular}

In order to evaluate if the different additives, wastes or recycling materials, can influence the

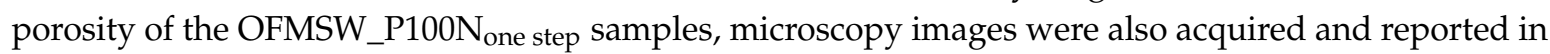
Figure 7D (with sawdust as additive) and Figure 7E (with coffee powder added). The average size of pores of OFMSW_P100N_10s one step and OFMSW_P100N_10c one step samples is also reported Table 4, evidencing that the presence of the fillers increases the porosity respect to OFMSW_P100N samples, probably due to their high hygroscopicity. The water imbibed by fillers, in fact, could cause an increase of total water content leading to the formation of higher voids volume during curing process. For this reason, the addition of sawdust strongly increases the average pores size. 
Table 4. Mechanical properties and density of dual step and one step process cured samples.

\begin{tabular}{ccccc}
\hline Samples & $\left.\boldsymbol{\sigma}_{\mathbf{R}} \mathbf{( M P a}\right)$ & $\boldsymbol{\varepsilon}_{\mathbf{R}}(\mathbf{m m} / \mathbf{m m})$ & $\mathbf{E}(\mathbf{M P a})$ & $\boldsymbol{\rho}\left(\mathrm{g} / \mathbf{c m}^{\mathbf{3}}\right)$ \\
\hline P100N & $2.84 \pm 0.76$ & $0.0054 \pm 0.002$ & $536.8 \pm 58.2$ & $0.37 \pm 0.04$ \\
OFMSW_P100N & $7.42 \pm 2.06$ & $0.0067 \pm 0.002$ & $1289.68 \pm 112$ & $0.55 \pm 0.06$ \\
OFMSW_P100N_one step & $5.54 \pm 0.35$ & $0.007 \pm 0.0014$ & $755 \pm 109$ & $0.46 \pm 0.04$ \\
OFMSW_P100N_10c_one step & $8.38 \pm 0.38$ & $0.0065 \pm 0.0021$ & $1355 \pm 79$ & $0.61 \pm 0.05$ \\
OFMSW_P100N_10s_one step & $1.32 \pm 0.07$ & $0.003 \pm 0.0004$ & $532 \pm 45$ & $0.40 \pm 0.03$ \\
\hline
\end{tabular}

The effect of the porosity on the mechanical properties of the sample were evaluated by compression tests. Typical flexural properties on P100N samples produced by dual-step and one-step processes are reported in Table 4.

Compared to the UF P100N system, addition of OFMSW in the dual step process allows a significant increase of strength and modulus. The increase of the strain at break, however, is much more limited. In this case, in facts, the difference between the blend UF/OFMSW and neat UF is comparable to the standard deviation associated to the measurements, also reported in Table 4 .

One way analysis of variance (ANOVA) [19] was performed on the strain at break. With one factor levels (UF P100N and OFMWS/UF blend) and five degrees of freedom for each level (six tests at each level) it is possible to estimate $p=0.29$, which is much higher than the significance level $\alpha=0.05$, indicating that the strain at break of the two averages are statistically equivalent, and the differences can be explained by considering the error associated to the measurement.

The production of UF/OFMSW blends by the one step process, though allows the reduction of the time and the costs associated to the treatment, involves a significant decrease of the flexural modulus. Even in this case, ANOVA was performed on the flexural strength and strain at break, also in view of the fact that the difference between the averages is comparable to the standard deviation of the measurements. For the strain at break, $p=0.77$ again indicates the statistical equivalence between the averages, whereas for the flexural strength, $p=0.01$ indicates that the one step process involves a statistically significant reduction compared to the dual-step process. This can be ascribed to a different evaporation rate for the two processes. In particular, the dual step process involves a further addition of water, which was lost during the sterilization step. On the other hand, the one-step process is characterized by the simultaneous cure and sterilization, further addition of water is not required. In the first process, the evaporation of water occurs at lower temperature reducing the release during the cure and, consequently, the porosity of the final component; in the latter one, water is entrapped in the OFMSW, the evaporation starts at higher temperatures, during the cure, causing a higher average pores diameter (Table 4 ).

However, it is also worth observing that in any case the flexural modulus and strength of UF/OFMSW produced by one step process are higher than the corresponding properties of UF P100N. In this case, direct comparison between the averages by ANOVA provided $p=1.3 \times 10^{-5}$ for the flexural strength and $p=1.3 \times 10^{-3}$ for the modulus. In contrast, for the strain at break, $p=0.14$ again indicates the statistical equivalence for UF P100N and UF/OFMSW produced by one step process. The increase of the flexural properties brought by the addition of OFMSW, both in the two step and in the one step process, can be attributed to a slower release of water during the cure, compared to the UF P100N. A lower evaporation rate involves, in turn, a reduction of porosities, especially in terms of pore diameter (Figure 7) leading to an increase in the mechanical behavior of the sample.

The mechanical properties of the material are also modified with the presence of additives. In particular, the addition of coffee powder involves an increase in the flexural modulus and strength, which achieve the highest values among all the tested formulations. Even in this case, based on ANOVA, it is not possible to draw any relevant conclusion on the strain at break, which is substantially equivalent to the strain at break of the other samples. On the other hand, addition of sawdust involves a statistically significant reduction of any of the flexural properties compared to UF/OFMSW processed 
by one step process, in this case also including the strain at break. This result is attributable to an increase in defects and imperfections caused by the additive, besides a higher porosity (Figure 7E).

Figure 8 shows the dependency of the elastic modulus and compression strength on the density of the samples. As previously explained, regardless of the treatment used or the filler added to the system, a lower density, which corresponds to higher porosity, involves a decay in mechanical properties.

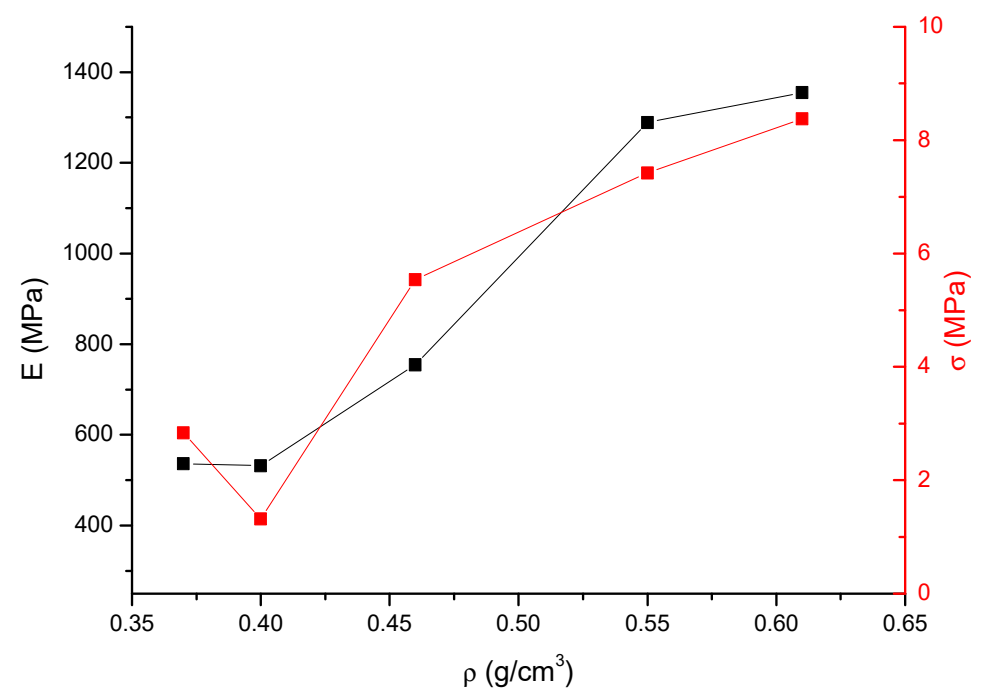

Figure 8. Elastic modulus and compression strength in function of density.

In Figure 9 some 3D pictures of the prototype machinery for OFMSW treatment are shown, appropriately designed for implementing the OFMSW stabilization and valorisation processes described before. The several sections and operating modes of the prototype machinery are briefly described; it is equipped by a weighting system, employing load cells applied to the loading chamber for weighting the amount of OFMSW delivered. When the total OFMSW weight reaches a target value, an automatic window is open and the chamber content is poured inside a next coarse shredding chamber, equipped with counter-rotating cylinders with grooves and notches for shredding the delivered OFMSW (Figure 9B, red box). Afterwards, the shredded material is poured into a cylindrical chamber below, where a rotating blade placed on its bottom, finely grinds the material and an underlying scraper blade removes the material deposits left on the bottom or side-walls of the chamber (see yellow box in Figure 9B). This chamber is equipped on the side walls of several nozzles for injecting high temperature steam and thermal film resistors for uniformly warming up the chamber walls for performing, by their combined action, the OFMSW sterilization.

Inside the cylindrical chamber a SEN0193 capacitive moisture sensor (DFROBOT, Milano, Italycompany, city, state abbrev if USA, country) was placed in tangential position to the inner surface for measuring water content of fine shredded OFMSW after sterilization and so for determining proper amounts of catalyser, UF P100N resin and additives [22]. After the OFMSW is poured through a hole at the bottom of cylindrical chamber into an underlying chamber where it is mixed with the additives (Figure 9C, blue box); the mixing of shredded OFMSW with additives is carried out by rotating a shaft equipped with blades along its entire length. On the top of mixing chamber, three electrically-actuated dispensers are placed with different capacities for UF P100N resin, catalyser and additives (coffee grounds, sawdust, etc.) (Figure 9C, purple box). Finally, the inertised OFMSW is injected, by means a cochlea conveyor, into a mold heated by thermal film resistors powered by a programmable controller for the curing step (Figure 9C, yellow box) [17]. The first prototype machinery of Figure 9 allows the treatment of about $5 \mathrm{Kg} /$ hour of OFMSW. Future machineries that we are now designing will treat until $25 \mathrm{Kg} /$ hour of OFMSW. 
A

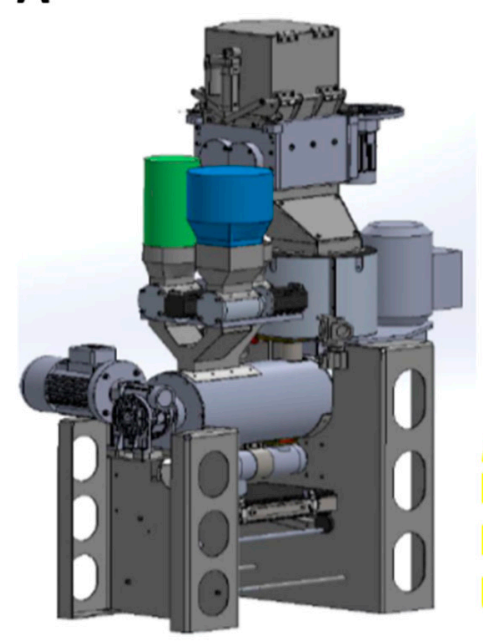

B

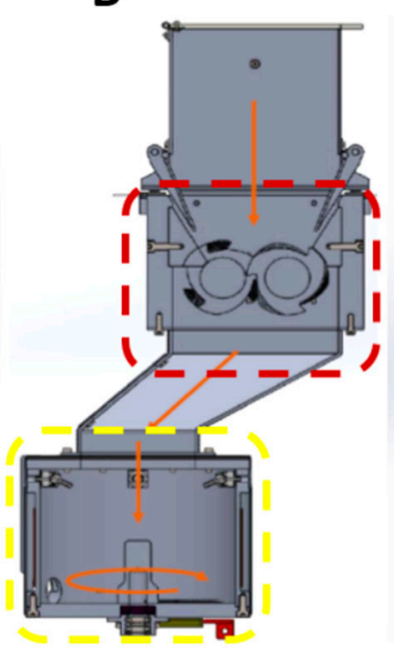

C

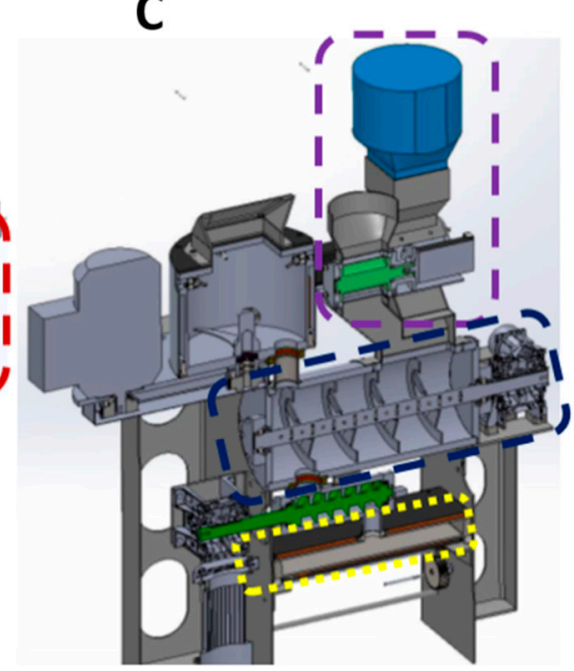

Figure 9. 3D pictures of the prototype machinery for OFMSW treatment: prospective view of the whole designed prototype (A), sectional view of the shredding system (B) and sectional view of whole prototype $(\mathbf{C})$.

\section{Conclusions}

The carried out research activity, supported by European Union's Horizon 2020 research and innovation program, aimed to realize an automated machinery, with different sizes depending on place where it has to be installed (domestic-residential use, restaurants as well as isolated mountain communities where the OFMSW's daily collection can be difficult), for targeted treatment of the conferred OFMSW by means of its transformation in an inertised, valorised and identifiable (namely traceable) products that can then be used for different purposes. The developed process will lead to several advantages compared to what generally happens today for OFMSW's disposal and treatment:

- The inertization and stabilisation allow a harmless and advantageous lasting storability of the treated-OFMSW;

- The harmlessness over time guarantees the eco-sustainability regardless subsequent path of the OFMSW-derived panels-bricks produced by the machinery;

- The waste's valorisation allows an extension of the possibilities of its reuse;

- The Radio Frequency identification (RFID) by using suitable wide-band low-cost passive UHF tags allows the traceability of the machinery's products ensuring targeted and optimal management of the re-use or storage of the valorized products;

- The codified identification allows the computerized management ensuring advantages for the public entities and citizens.

Specifically, in this paper two original processes (called dual and one step) for transforming the organic waste (OFMSW) into an inert, odorless and sanitized material were proposed. To this aim, new green composites were realized through the incorporation of the OFMSW finely ground in a thermosetting urea-formaldehyde (UF) based resin. OFMSW /UF composites produced with the two-step method were firstly analysed by dynamic rheological analysis, in order to select the optimal curing conditions, even in presence of OFMSW. The mechanical results obtained on the cured samples produced with both dual and one step processes, highlight that the OFMSW /UF composites are characterized by higher mechanical properties compared to the neat resin. This last result was attributed to a decreased water evaporation rate, due to the presence of OFMSW and, in turn, to a less porous composites structure, as confirmed by optical microscopy analysis. Both methods proposed in this paper could be considered suitable for the production for example of Medium-density fibreboard (MDF)-like panels for building applications or thermal and acoustic insulating waste-based bricks to be 
used as filler in non-structural applications, as in detail previously discussed. A rough cost estimation of the developed procedure is presented in second part of the present paper, proving the potential cost saving compared to the neat matrix [17]. Such a cost estimation must account for the fact that, compared to the standard processing of the UF resin, an additional cost is given by the sterilization, but the production of the blend, allows to reduce the cost due to the reduced UF consumption. In addition, the detailed results on the mechanical and thermal specifications obtained by the OFMSW-derived bricks or panels, made using the prototype machinery described above at the design stage, will be illustrated in another scientific work being prepared but here we can anti-cipate that the obtained values will allow their use in the proposed applications based on the existing standards on the technical specifications and low emission level of free formaldehyde in the air.

Finally, an important advantage of this project, in terms of the environmental impact, lies in the reduction of $\mathrm{CO}_{2}$ emissions, since the organic waste, if not properly and quickly treated, becomes a source of carbon dioxide emissions.

Author Contributions: F.F., R.S., R.D.F. and S.M. performed the experiments. C.E.C. and A.G. supervised the work. P.V. is the scientific responsible of the project, M.P., A.P. and F.P. performed the microbiological experiments.

Funding: This work is funded by the project POIROT with CUP code B89J17000370008 supported by the MISE (Ministry of Economic Development) of Italy within the European Union's Horizon 2020 research and innovation program, in collaboration with Italian companies Medinok SpA (Volla, NA) and Arter Srl (Castello di Cisterna, NA).

Acknowledgments: The authors gratefully acknowledge SADEPAN CHIMICAL S.r.l. for supplying the Urea-Formaldehyde resin and for technical support.

Conflicts of Interest: The authors declare no conflict of interest.

\section{References}

1. European Commission. Eurostat. Available online: ec.europa.eu/eurostat/statistics-explained/index.php/ Municipal_waste_statistics (accessed on 19 June 2019).

2. Tickner, J.A.; Morone, P.; Tartiu, V. New business models, ethic, legislation and economics. Curr. Opin. Green Sustain. Chem. 2017, 8, 1-48.

3. Environmental Protection Agency. Wastes, Municipal Solid Waste. Available online: https://archive.epa.gov/ epawaste/nonhaz/municipal/web/html (accessed on 19 January 2017).

4. European Commission. Food Safety, Food, Food Waste. Available online: ec.europa.eu/food/safety/food_waste_ en (accessed on 27 January 2017).

5. Campuzano, R.; González-Martínez, S. Characteristics of the organic fraction of municipal solid waste and methane production: a review. Waste Manag. 2016, 54, 3-12. [CrossRef] [PubMed]

6. Cobo, S.; Dominguez-Ramos, A.; Irabien, A. Minimization of resource consumption and carbon footprint of a circular organic waste valorization System. ACS Sustain. Chem. Eng. 2018, 6, 3493-3501. [CrossRef]

7. Cobo, S.; Dominguez-Ramos, A.; Irabien, A. Economics of Enhancing Nutrient Circularity in an Organic Waste Valorization System. Environ. Sci. Technol. 2019, 53, 6123-6132. [CrossRef] [PubMed]

8. Matsakas, L.; Gao, Q.J.; Jansson, S.; Rova, U.; Christakopoulos, P. Green conversion of municipal solid wastes into fuels and chemicals. Electron. J. Biotechnol. 2017, 26, 69-83. [CrossRef]

9. Mohan, S.V.; Nikhil, G.N.; Chiranjeevi, P.; Reddy, C.N.; Rohit, M.V.; Kumar, A.N.; Omprakash, S. Waste biorefinery models towards sustainable circular bioeconomy: Critical review and future perspectives. Bioresour. Technol. 2016, 215, 2-12. [CrossRef] [PubMed]

10. Mirabella, N.; Castellani, V.; Sala, S. Current options for the valorization of food manufacturing waste: A review. J. Clean. Prod. 2014, 65, 28-41. [CrossRef]

11. Haque, M.A.; Kachrimanidou, V.; Koutinas, A.; Lin, C.S.K. Valorization of bakery waste for biocolorant and enzyme production by Monascus purpureus. J. Biotechnol. 2016, 231, 55-64. [CrossRef] [PubMed]

12. Satpute, S.K.; Plaza, G.A.; Banpurkar, A.G. Biosurfactants' production from renewable natural resources: example of innovativeand smart technology in circular bioeconomy. Sciendo 2017, 25, 46-54. [CrossRef]

13. Rentizelas, A.A.; Tolis, A.J.; Tatsiopoulos, I.P. Logistics issues of biomass: The storage problem and the multi-biomass supply chain. Renew. Sustain. Energy Rev. 2009, 13, 887-894. [CrossRef] 
14. Enno, B.; Angenendt, E. Status quo and perspectives of biogas production for energy and material utilization. GCB Bioenergy 2019, 11, 9-20.

15. Mangold, A.; Lewandowski, I.; Hartung, J.; Kieser, A. Miscanthus for biogas production: Influence of harvest date and ensiling on digestibility and methane hectare yield. GCB Bioenergy 2019, 11, 50-62.

16. Cerda, A.; Artola, A.; Barrena, R.; Font, X.; Gea, T.; Sánchez, A. Innovative Production of Bioproducts From Organic Waste Through Solid-State Fermentation. Front. Sustain. Food Syst. 2019, 3, 63. [CrossRef]

17. Corcione, C.E.; Ferrari, F.; Striani, R.; Visconti, P.; Greco, A. An innovative green process for the stabilization and valorization of organic fraction of municipal solid waste (OFMSW) II part: Optimization of the curing process. Appl. Sci. 2019, 9, 3702. [CrossRef]

18. Lado, B.H.; Yousef, A.E. Alternative food-Preservation technologies: Efficacy and mechanisms. Microbes Infect. 2002, 4, 433-440. [CrossRef]

19. Montgomery, D. C Introduction to Statistical Quality Control, 2nd ed.; John Wiley and Sons: New York, NY, USA, 1991.

20. Rutala, W.A.; Stiegel, M.M.; Sarubbi, F.A., Jr. Decontamination of laboratory microbiological waste by steam sterilization. Appl. Environ. Microbiol. 1982, 43, 1311-1316.

21. Ferrari, F.; Striani, R.; Esposito, C.C.; Greco, A. Valorization of food industries wastes for the production of poly(vinyl) alcohol (PVA) biodegradable composites. Front. Mater. 2019, 6, 177. [CrossRef]

22. Fazio, R.D.; Corcione, C.E.; Greco, A.; Ferrari, F.; Striani, R.; Catarinucci, L.; Colella, R.; Mighali, V.; Patrono, L.; Sergi, I.; et al. Sensors-based treatment system of the organic waste with RFID identification and on-cloud traceability. In Proceedings of the IEEE Xplore Proceeding of IEEE International Workshop on Advances in Sensors and Interfaces (IWASI), Otranto, Italy, 13-14 June 2019; pp. 245-250.

(C) 2019 by the authors. Licensee MDPI, Basel, Switzerland. This article is an open access article distributed under the terms and conditions of the Creative Commons Attribution (CC BY) license (http://creativecommons.org/licenses/by/4.0/). 